\title{
A call for de-policing crisis responses: Distressed children and youth caught between the mental health and police systems
}

\author{
Dr. Maria Liegghio, ${ }^{*}$ Herberth Canas, ${ }^{\dagger}$ Alexis H. Truong, ${ }^{\ddagger}$ and Salomi Williams ${ }^{\S}$
}

\begin{abstract}
In this paper, we present the outcomes of a narrative study of 13 interviews with six child and youth mental health practitioners and seven caregivers with a child between 12 and 24 years old involved with the mental health system and with a history of police involvement. The focus of the interviews was on the experiences of young people involved with the mental health system, and their caregivers, with police encounters. Two categories of themes emerged. Presented here are the outcomes that show the contradictions between the child and youth mental health and police systems as contributing factors to the stigmatization and criminalization of psychiatrically distressed children and youth. A call is made for a collaboration between the mental health and police systems rooted in a commitment for de-policing crisis responses in child and youth mental health.
\end{abstract}

Key Words Collaboration; criminalization; policing; psychiatrization; stigmatization.

\section{POLICE ENCOUNTERS IN CHILD AND YOUTH MENTAL HEALTH}

\begin{abstract}
Despite a decade of emerging scholarship, increased public attention, and numerous government inquests, concerns about the policing of persons living with a mental health issue continue (Braidwood Commission, 2009; Brink et al., 2011; Chammartin et al., 2011; Coleman \& Cotton, 2010; Cotton \& Coleman, 2008; Eden 2014; Livingston et al., 2014; Sloly, 2021). Generally, the existing scholarship focuses on the experiences of psychiatrically involved or distressed adults and not necessarily those of children and youth. For adults, estimates suggest that approximately $7 \%$ to $15 \%$ of police calls involve an individual living with a mental illness (Cotton \& Coleman, 2008), and that approximately $65 \%$ of adults newly admitted to inpatient and community psychiatric services had had some sort of encounter with police over their lifetime (Brink et al., 2011). For children and youth, in studies examining police referrals and arrest rates, youth using community-based mental health services were nearly three times more likely to be referred to police (Vander Koep et al., 1997), while those in group home settings had higher arrest rates than those in inpatient psychiatric settings (Robst
\end{abstract}

et al., 2013). In one of the only studies specifically focused on examining policing and children's mental health, Liegghio and colleagues (2017) found that of a community sample of 1,449 children and youth (birth to 24 years old) accessing mental health services, approximately $16 \%$ or one in six had had police involvement related to their mental health.

Similar to adults, the main reasons for police involvement were: for support to de-escalate a highly charged verbal or physical situation involving a distressed child; because of risks or threats of harm to self and/or others, in particular to parents and siblings; due to concerns related to a child's behaviour in the community, such as property damage and shoplifting; and for physical interventions when restraints or transports to hospital were required because of suicide threats or attempts (Liegghio \& Jaswal, 2015; Liegghio, 2017; Liegghio et al., 2017; Liegghio et al., 2020). In most instances, encounters with police were described as helpful for de-escalating conflict situations but unhelpful as a mental health intervention, because of the associated stigmatization, criminalization, and psychiatrization of the child, caregivers, and family (Liegghio, 2017; Liegghio, et al., 2020).

Based on adults' experiences, the main concerns with using police for mental health support are the criminalization 
of mental illness and of persons deemed to have a mental illness. In particular are concerns about the inappropriate use of excessive force and physical restraints-in some instances causing death; the policing of mental illness; and the inappropriate treatment of persons living with a mental health issue by the criminal justice versus the mental health system (Corrigan et al., 2005; Fry et al., 2002; Morabito et al., 2012; Watson et al., 2008). Criminalization is cited as a major form of structural or institutional discrimination for psychiatrized adults (Chaimowitz, 2012; Corrigan et al., 2005; Gur, 2010). For children and youth, criminalization is also beginning to emerge as a form of institutional discrimination in which young people experiencing psychiatric issues are dealt with by the police and the criminal justice systems rather than the mental health system (Liegghio \& Jaswal, 2015; Liegghio et al., 2017; Liegghio et al., 2020). In the adult sector, reliance on police for mental health support has evolved over time.

\section{Reliance on Police as a "Necessary Ally"}

In the adult sector, many argue that the use of police and police services as a mental health intervention is connected to developments in the mental health system and the expansion of mental health legislation (Cummins \& Edmondson, 2016; Iacobucci, 2014; Kelly, 2005; Lamb et al., 2002; Wolff, 2005; Yang et al., 2018). Traced to the 1960s, the deinstitutionalization movement sought to shift the primary setting of mental health care and treatment from in-patient, psychiatric institutions and asylums to community settings. The general understanding, which continues to this day, is that individuals facing psychiatric issues are best served living as members of their communities and connected to their families (Cummins, 2011). However, a strong critique of deinstitutionalization is that it occurred without the simultaneous development and implementation of appropriate community services and supports (Cummins \& Edmondson, 2016; Kelly, 2005; Sloly, 2021; Wolff, 2005). Without adequate community-based mental health and social supports, individuals and families were pushed to rely on other systems, in particular, police services and the legal system (Cummins \& Edmondson, 2016; Iacobucci, 2014; Kelly, 2005; Lamb et al., 2002; Sloly, 2021; Wolff, 2005; Yang et al., 2018).

Simultaneously, through the expansion of mental health legislation, police and police services have been called upon to intervene, specifically in situations where a person is perceived to be a risk or to be a threat of harm to themselves or others. For some police services, it has been noted that calls for support are increasingly made by mental health service providers (Sloly, 2021). With adults, under the Mental Health Act, police services are now relied on to provide physical interventions, including restraints, escorts to hospital, and the enforcement of involuntary committal and community treatment orders (Cummins \& Edmondson, 2016; Iacobucci, 2014). Despite concerns about the policing of persons living with a mental health issue, police services are inadvertently positioned as a "necessary ally," while for responding officers, providing mental health supports has become central to their legal roles and mandates. However, in the case of psychiatrically distressed children and youth, very little is known about the reliance on police services by the child and youth mental health system. This paper addresses that gap.

\section{METHODS}

The research reported here is a pilot to a larger mixed-methods study currently under way. While the larger study explores the meaning young people make of their experiences of "distress" and of accessing and using crisis mental health services, including police, the pilot explores the lived experiences of children and youth involved with the mental health system, and their caregivers, with policing and police encounters. Using a narrative study design, a thematic content analysis was conducted of thirteen $(n=13)$ semi-structured, one-to-one interviews with six $(n=6)$ frontline child and youth mental health practitioners and seven $(n=7)$ caregivers with a child between 12 and 24 years old involved with the mental health system and with a history of police involvement. The research questions focused on gathering information about the subjects' lived experiences of police encounters from the perspective of caregivers and of child and youth mental health practitioners. Ethics approval was obtained through the Office of Research Ethics at York University and the service agencies involved as collaborators.

\section{Recruitment and Sampling}

Recruitment occurred through two community-based mental health agencies located in a large urban area near Toronto, Canada. The agencies have long-standing histories of providing a continuum of mental health assessment and treatment services to children and youth from birth to 24 years old and their caregivers and families. Recruitment of both the mental health practitioners and caregivers consisted of connecting with service managers within the organizations and arranging for the distribution of two letters of invitation (one for frontline practitioners and the second for caregivers) to participate in the study. In both letters, prospective participants were directed to contact the researcher (first author) directly. Full information about the study (i.e., purpose and risks and benefits) was then provided, appropriate practitioners and caregivers were invited to participate, and an informed consent form was signed prior to commencing the interviews.

Purposive sampling was used to identify both the practitioner and caregiver participants. The criteria for inclusion of caregiver participants was being a caregiver with a child between 12 and 24 years old, nearing the end of their mental health treatment or who had used mental health services within the previous two years and who had had police involvement for a mental health concern. The criteria for inclusion of practitioner participants was being a mental health professional (i.e., social worker, child and youth worker, etc.) with a minimum of two years of frontline experience providing mental health support to children and youth 12 to 24 years old. Caregivers were given $\$ 65.00$ honoraria, and practitioners a \$20.00 gift card.

\section{Data Collection and Analysis}

The pilot data was collected between August 2016 and May 2018 and consisted of in-depth, semi-structured, one-to-one interviews with caregivers and child and youth mental health practitioners. The interviews were 1 to 1.5 hours, audio taped, and transcribed verbatim. The data for analysis consisted of the demographic information collected about the participants and the 13 transcripts. 
Data analysis of the transcripts consisted of an inductive process using thematic content analysis (Braun \& Clarke, 2006). The analysis followed three steps: 1) a general review of the transcripts for themes and patterns, similarities and differences, and a range of responses between caregivers; 2) a line-by-line review identifying discrete segments of meaning and concepts until the classifications of the concepts were exhausted and saturation was achieved; and 3) reorganization of the identified concepts into categories of themes that explained the phenomena under study. The goodness or rigour of the data depended on the consideration of all possible meaning for concepts as they were identified and labelled throughout the process (Weiss, 1994). As a validation of the categories, an inter-coder comparison was also conducted (Burnard, 1991). When presenting the findings, identifying information has been altered and pseudonyms used to protect the confidentiality of the practitioners, the caregivers, and their family members.

\section{Limitations of the Study}

The main limitations of the study are related to the sample and sampling of the participants. Participants were recruited primarily through two programs for young people with severe or chronic mental health issues. The programs were provided through two community-based mental health agencies. Consequently, the findings reflect a small range of experiences of mental health practitioners and caregivers, specifically those accessing or working in community-based (versus hospital) services. Presumably, caregivers with children facing moderate or situational issues may have different experiences of police encounters. In addition, diversity along the lines of race, class, gender, culture, sexual orientation, immigration status, Indigeneity, family status, and type of mental health issue was also not well represented.

\section{RESULTS}

\section{Participants}

There were a total of 13 participants. Six were front-line child and youth mental health practitioners and seven were caregivers with a child between 12 and 24 years old involved with the child and youth mental health system and with a history of police involvement. Tables I and II summarize the demographic information of the mental health practitioners and caregivers, respectively.

Two main categories of themes emerged from the interviews. Reported elsewhere, one category described the reasons and nature of the encounters with police and police services (see Liegghio et al., 2020). Generally, police services were accessed for support to de-escalate a highconflict verbal or physical situation with a distressed child, and when police were accessed, the encounters were most often described as negative and resulted in experiences of stigma and criminalization. In this paper, we present the outcomes of the reliance on police services by the child and youth mental health system and the ways in which, through police charging practices, both the mental health system and the police are implicated in the criminalization of distressed children and youth. A call is made for the de-policing of crisis responses with children and youth-defined as the
TABLE I Demographic information of the child and youth mental health practitioners

\begin{tabular}{|c|c|}
\hline Characteristic & Number (n) \\
\hline Total & 6 \\
\hline \multicolumn{2}{|l|}{ Sex/Gender } \\
\hline Female & 5 \\
\hline Male & 1 \\
\hline \multicolumn{2}{|l|}{ Race } \\
\hline Caucasian & 4 \\
\hline Racialized (Black) & 2 \\
\hline \multicolumn{2}{|l|}{ Profession } \\
\hline Social worker (MSW) & 4 \\
\hline Counselling degree (masters) & 1 \\
\hline Child and youth worker (college) & 1 \\
\hline $\begin{array}{l}\text { Number of years working in child and youth } \\
\text { mental health }\end{array}$ & $4,4,7,9,11,13$ \\
\hline Mean & 8 \\
\hline
\end{tabular}

realignment of community services with an intentional and purposeful move away from relying on police for mental health support.

\section{Child and Youth Mental Health Reliance on Police Services}

According to the perspectives of mental health practitioners and caregivers, as reported elsewhere (refer to Liegghio et al., 2020), police services were most often accessed for support to de-escalate high-conflict physical, verbal, or emotionally charged situations involving a distressed child or youth. Police were called not only by parents and youth themselves but also by mental health practitioners working in counselling, residential, or drop-in centres. One practitioner, Jill, described some of the reasons police were called:

Police have been called numerous times to their house for verbal aggression, sometimes physical, often physical aggression, so punching, hitting, getting into physical fights usually with family members, running away from home, not coming home for curfew, skipping school.

Across the caregiver and practitioner interviews, reliance on police emerged from a service need and an expectation that police interventions would result in the child or youth being connected, in particular, to crisis or emergency mental health care. Interviewees from different perspectives-Tara, a mother, and practitioners Angela and Mark-poignantly describe their expectations as unmet.

Tara [mother]: [While police were responding in the home], I fully expected them to take her back up to the hospital [for an emergency assessment for suicidal ideation and threats]. Anyways, they came back out after talking to her for, maximum 15 minutes, and the younger of the two cops said to me, well, we're just going to leave her with you because 
Table II Demographic information of the caregivers

\begin{tabular}{|c|c|}
\hline Characteristic & Number (n) \\
\hline Total & 7 \\
\hline \multicolumn{2}{|l|}{ Sex/Gender } \\
\hline Female/Mother & 6 \\
\hline Male/Father & 1 \\
\hline Age (at the time of the interview), years & $39,49,52,52,53,54,59$ \\
\hline Mean & 50 \\
\hline \multicolumn{2}{|l|}{ Race } \\
\hline Caucasian & 4 \\
\hline $\begin{array}{l}\text { Racialized (Black, Latino/a; Middle } \\
\text { Eastern) }\end{array}$ & 3 \\
\hline \multicolumn{2}{|l|}{ Highest education } \\
\hline High school & 1 \\
\hline Some college or college degree & 3 \\
\hline $\begin{array}{l}\text { Some or undergraduate university } \\
\text { degree }\end{array}$ & 2 \\
\hline Doctoral university degree & 1 \\
\hline \multicolumn{2}{|l|}{ Family composition } \\
\hline One-parent household & 3 \\
\hline Two-parent household & 4 \\
\hline \multicolumn{2}{|l|}{ Annual family income } \\
\hline$\$ 39,000$ and below & 2 \\
\hline$\$ 40,000$ to $\$ 49,000$ & 1 \\
\hline$\$ 50,000$ to $\$ 59,000$ & 3 \\
\hline$\$ 150,000$ & 1 \\
\hline
\end{tabular}

Age and gender (male/female) of

identified child

$\begin{array}{lc}14 & 1 \text { male, } 1 \text { female } \\ 15 & 1 \text { male, } 1 \text { female } \\ 16 & 1 \text { male } \\ 17 & 1 \text { male, } 1 \text { female }\end{array}$

Number of mental health diagnoses

of identified child

One diagnosis

2

Two diagnoses

4

Three or more diagnoses

1

Nature of identified child's mental health issues

Depression

3

Anxiety

3

Suicide talk/ideation

2

ADHD

ODD

3

2

Query psychosis (hearing voices)

Query Asperger's

1

Trauma counselling/no diagnosis

$\mathrm{ADHD}=$ attention deficit and hyperactivity disorder; ODD = oppositional defiance disorder. we don't think she's going to do anything, and they handed me the knife back. And I just looked at them and I felt like saying-really?...Because I could not get her to go to counselling....I thought when the police came that this would be the answer... why wouldn't they take her up to the hospital? I mean, this kid has threatened to hurt herself, she's threatened to hurt other people in the home.

Angela [practitioner]: It frustrated me, and it angered me...knowing that this kid had been to the hospital so many times, I don't know, it blows my mind that they didn't come up with a different plan about involving crisis services. And it baffled me-it made me wonder, how much knowledge do the police have about the mental health services that are out there, because there are so many, and I couldn't understand why this kid wasn't being connected with any of them.

Mark [practitioner]: We had one client [in the residential treatment home] that would always make claims, I'm going to hurt myself...police are, "oh, I have to take him" or sometimes they just come in, "okay, I had a talk with him, he's good." And then hours later we're calling them back again because they're either destroying property or making the environment unsafe for other clients....Police that have come, they say either "we can't do anything unless they [the child] say they're a harm to themselves." Sometimes I find it a little bit frustrating because we're calling for their assistance because we feel the child is not safe, the child is assaulting other people and sometimes it just feels like our hands are tied, and their hands are tied too.

In another instance, one practitioner, describing how mental health and police systems worked together to intervene with a youth who had attempted to commit suicide by jumping from a public building, explains her frustration with police coming in and "undoing" her work as a mental health worker.

Lucy [practitioner]: So when the police came, it really felt that everything that myself and my co-worker had done to kind of bring him [distressed youth] to a place where he was calm, he still wasn't in touch with reality, [but he] was able to be calm and talk with us and start processing the situation. The police kind of came in, stormed in, and very much treated him like he was a criminal and dangerous. In some ways, I understand because we were in a public space, but at the time, the youth was really in a place where he would have been very willing to comply and go with them to the hospital...they dealt with the situation very poorly, and it ended up being just a huge breach in our relationship with the youth, and we didn't see him for probably two or three years, and then he came back and we were able to kind of re-establish that relationship. 
What was striking across these experiences was the ways in which practitioners implicated police for not providing-or connecting the child or youth with-appropriate supports, while simultaneously failing to consider the ways in which they too, as mental health service providers, were not necessarily supporting the children's distress and addressing the safety concerns (Sestoft et al., 2014). In other words, for caregivers like Tara, connecting her daughter to mental health services would have meant being connected to the very supports provided by practitioners like Mark, Angela, and Lucy. This is a contradiction that signals a gap in the existing service system-implicating police while failing to recognize that reliance on police services may be occurring because of ways the child and youth mental health system is organized and ill-equipped to provide adequate crisis support to young people and their families. Although police reliance was perceived as necessary, encounters with police were fraught with concerns about the criminalization of children and youth.

\section{Laying Charges-Caught Between Systems (Not) Working Together}

Across both the practitioner and caregiver interviews, calls to police for mental health support raised concerns about the criminalization of children and youth through verbal and physical threats, and in particular, police decisions and charging practices. Examples of the concerns about charging practices are best described by practitioners Jill, Karen, and Angela.

Jill: After several occasions of them [responding officers] picking him [youth] up, taking him to the hospital, and then him being released from the hospital, they [police] arranged for a meeting together with him, his mother and the [police] supervisor...to problem-solve around what they were going to do about this situation, because they [police] were telling him that it was wasting their time, you know, taking him to the hospital and then he's actually fine, and the result was that if he called one more time, he was going to be charged with public mischief.

Karen: When I get feedback from clients about their experiences with police, I sense that families want to use the police as a resource, but when they're getting reminders about consequences and charges, I think it instils fear...I know there's been lots of situations where eventually clients [youth], parents, for example, would stop phoning if their kids were coming at them with knives and just say, well, the police won't get here on time, and if they do, they're just going to threaten to charge my kid.

Angela: [Describing the experiences of a youth with whom police intervened because of a suicide attempt]...It really stuck with me. It really upset me that rather than trying to form some sort of plan around getting him supports around his mental health, they [police] just told him that if he called one more time, he was going to be charged, and then he was. And this youth is over 18, he is now 21 and this all happened within the last year, so these are charges that are going to be on his record.

In an effort to understand the charging and arrest rates of youth receiving mental health treatment in community-based settings, Robst and colleagues (2013) note that over time with repeated calls, responding officers may become desensitized to the mental health issues and less tolerant of the young person's and mental health system's need for support. In other words, responding officers may be threatening or laying charges because of the belief that, once formally charged, the young person can be "forced" into treatment through the youth justice system. However, these beliefs are misguided, as other research suggests that the youth justice system is ill-equipped to support the mental health needs of its criminally involved youth (Drerup et al., 2008; Moskos et al., 2007; Odgers et al., 2005; Peterson-Badali et al., 2015). Essentially, these outcomes suggest psychiatrically distressed children and youth and their caregivers are passed back and forth and getting caught between the mental health and police systems - caught by the ways the systems are working, or more precisely, not working, together, the result being the criminalization of young people facing mental health crises.

\section{Calling for De-Policing Crisis Responses in Child and Youth Mental Health}

As these outcomes suggest, caregivers and mental health practitioners are turning to police services for similar reasons-because of safety concerns and for support for distressed children and youth. In their mental health practices, practitioners are advising parents to call police, while also, as a system, turning to police for support. Practitioners, caregivers, and presumably responding officers share similar aims, which is to connect the child or youth to appropriate and timely mental health care at the moment of need-at the moment of the immediate crisis. The reliance on police as a necessary ally sheds light on structural issuesin particular, gaps in services and the lack of coordination and collaboration between the police and child and youth mental health systems - the result being the criminalization of distressed children and youth in their encounters with both the police and mental health systems. As suggested by these findings, young people's criminalization involved being passed and caught between the two systems, and having their experiences of distress "criminalized" by being made to feel as though they were doing something wrong when they called police for support. A potential result was unmet expectations and fear of police related to threats of being charged or the actual laying of charges in subsequent calls, thus marking the young person as "criminal." Reported in an earlier issue of this journal, concerns about being perceived or treated as a criminal are an example of experiences that mark young people's encounters with police as negative and stigmatizing (Liegghio, et al., 2020).

These outcomes clearly show a need for models of practice that address the structural issues that perpetuate the reliance on police services for mental health support. The goal is ultimately to have distressed young people supported by mental health services. The main issue is the lack of adequate community services (Sloly, 2021). In working with 
adults, one approach has police, mental health, and social service systems working together, collaborating to provide a coordinated and integrated community response, not only to address the immediate crisis but also to address underlying factors that may contribute to and propel individuals and families into crisis situations, and offer support (Fisher et al., 2006; Lamanna et al., 2018; Lord \& Bjerregaard, 2014; Sestoft et al., 2014). Although we can speculate, based on adults' experiences, that these models may be viable for distressed children and youth, very little is known about their appropriateness for and applicability to young people and their families. Thus, there is a need for further research about young people's experiences of distress and of accessing and using mental health services, including crisis and police services, for support.

Underlying these recommendations for institutional change is a recognition of the need to move away from relying on police services for mental health support (Fisher et al., 2006; Lamanna et al., 2018; Lord \& Bjerregaard, 2014; Sestoft et al., 2014; Sloly, 2021). Building on this idea, we call for the de-policing of crisis responses with distressed children and youth. Essentially, de-policing crisis responses means addressing the contradictions: moving away from having a system that inadvertently pushes children and youth, and their families, to rely on police for mental health support to building a coordinated and integrated social service and child and youth mental health system that can respond more effectively to distress, crises, and safety concerns. As suggested by one Ontario-based police service, a strategy for de-policing crisis responses could be extending the authority of 911 emergency dispatchers to screen for safety (the main rationale for police involvement) and, when appropriate, to dispatch a team of mental health workers as first responders, rather than police, fire, or ambulance (Sloly, 2021). Such a strategy expands our current social or societal understanding of emergency services to include mental health workers among first responders.

Moreover, because of ongoing concerns about the inappropriate use of police force, in some instances causing death (Corrigan et al., 2005; Fry et al., 2002; Morabito et al., 2012; Watson et al., 2008), de-policing crisis responses necessitates a critical examination of what it means to rely on "policing," "police officers," and "police services" to ensure personal and public safety. This examination needs to traverse sectors and social institutions, arguing that the work of community safety and well-being falls to all of us within a society. Such an examination is particularly important for communities that have faced and continue to face institutional forms of violence - as in the case of institutional racism encountered by members of Indigenous, Black, and other minority communities (Alberton, et al., 2019; Aymer, 2016; Dukes \& Kahn, 2017; Green, 2006; Miller \& Vittrup, 2020). Contemporary policing requires an examination of the ways in which "mental health support intersects with other issues like race, culture, health equity and gender" (Sloly, 2021, p. 3). We purport, based on the outcomes of our work, that "age" as a diversity category-a young person's status as a "child" — needs to be added to that list. To conclude, de-policing child and youth mental health would mean building a system of mental health services served by practitioners equipped with the knowledge, skills, tools, and resources to respond to young peoples' experiences of distress, including when safety may be an issue. In other words, we can no longer rely on the rationale that "safety concerns" necessitate police involvement, given all we know about the harms occurring due to the reliance of the mental health system on police services for mental health support. We need to expand our understanding of safety and well-being to include community approaches.

\section{ACKNOWLEDGEMENTS}

We would like to acknowledge EveryMind Mental Health Services (formerly Peel Children's Centre and Nexus Youth Services), and especially Dr. Kathy Sdao-Jarvie, Chief Officer, System Planning and Accountability, for their unwavering commitment to improving mental health supports for children and youth and their families. We would also like to acknowledge the parents and front-line mental health practitioners who took time from their busy schedules to participate in this study. Their experiences and knowledge make important contributions to advancing our understanding of the nature of policing and police encounters, as well as of the ways to improve service delivery in children's mental health.

\section{CONFLICT OF INTEREST DISCLOSURES}

The authors declare that there are no conflicts of interest.

\section{AUTHOR AFFILIATIONS}

* Associate Professor, School of Social Work, York University, Toronto, ON, Canada; ${ }^{+}$Research Associate, School of Social Work, York University, Toronto, ON, Canada; Research Associate, Shifting Ways; ‡ Assistant Professor, Department of Criminology, Faculty of School of Social Sciences, University of Ottawa, Ottawa, ON, Canada; $\$$ BSW, Research Assistant, School of Social Work, York University, Toronto, ON, Canada.

\section{REFERENCES}

Alberton, A., Gorey, K., Angell, B., \& McCue, H. (2019). Intersection of Indigenous peoples and police: Questions about contact and confidence. Criminology and Criminal Justice, 61 (4), 101-119.

Aymer, S. (2016). "I can't breathe": A case study - Helping Black men cope with race-related trauma stemming from police killing and brutality. Journal of Human Behavior in the Social Environment, 26(3-4), 367-376

Braidwood Commission. (2009). Restoring public confidence: Restricting the use of conducted energy weapons in British Columbia. Victoria, BC: Author. http://www.braidwoodinquiry.ca/report

Braun, V., \& Clarke, V. (2006). Using thematic content analysis in psychology. Qualitative Research in Psychology, 3(2), 77-101.

Brink, J., Livingston, J., Desmarais, S., Greaves, C., Maxwell, V., Michalak, E., Parent, R., Verdun-Jones, S., \& Weaver, C. (2011). A study of how people with mental illness perceive and interact with the police. Calgary, AB: Mental Health Commission of Canada.

Burnard, P. (1991). A method of analysing interview transcripts in qualitative research. Nurse Education Today, 11, 23-37.

Chaimowitz, G. (2012, February). The criminalization of people with mental illness. Canadian Journal of Psychiatry, 57(2), 1-7.

Chammartin, N., Ogaranko, C., \& Froese, B. (2011). Equality, dignity and inclusion: Legislation that enhances human rights for people living with mental illness. Calgary, AB: Mental Health Commission of Canada.

Coleman, T., \& Cotton, D. (2010). Interactions with persons with a mental illness: Police learning in the environment of contemporary policing. Calgary, AB: Mental Health Commission of Canada.

Corrigan, P., Watson, A., Byrne, P., \& Davis, K. (2005, October). Mental illness stigma: Problem of public health or social justice? Social Work, 50(4), 363-368. 
Cotton, D., \& Coleman, T. (2008). A study of police academy training and evaluation for new police officers related to working with people with mental illness. Calgary, AB: Mental Health Commission of Canada.

Cummins, I. (2011). Mental health services in the age of neo-liberalism. Social Work and Social Policy in Transition, 1 (2), 55-74.

Cummins, I., \& Edmondson, D. (2016). Policing and street triage. The Journal of Adult Protection, 18(1), 40-52.

Drerup, L., Croysdale, A., and Hoffmann, N. (2008). Patterns of behavioral health conditions among adolescents in a juvenile justice system. Professional Psychology Review, 39(2), 122-128.

Dukes, K., \& Kahn, K. (2017). What social science research says about police violence against racial and ethnic minorities: Understanding the antecedents and consequences - An introduction. The Journal of Social Issues, 73(4), 690-700.

Eden, D. (2014). Verdict explanation: Inquest into the deaths of Reyal Jardine-Douglas, Sylvia Klibingaitis and Michael Elgin Jr. Toronto, ON: Office of the Chief Coroner. http://www.mcscs. jus.gov.on.ca/english/Deathlnvestigations/office_coroner/ PublicationsandReports/OCC_pubs.html

Fisher, W., Silver, E., \&Wolff, N. (2006). Beyond criminalization: Toward a criminologically informed framework for mental health policy and services research. Administration and Policy in Mental Health and Mental Health Services Research, 33(5), 544-557.

Fry, A., O'Riordan, D., \& Geanellos, R. (2002, July). Social control agents or frontline carers for people with mental health problems: Police and mental health services in Sydney, Australia. Health and Social Care in the Community, 1014), 277-286.

Green, J. (2006). From Stonechild to social cohesion: Anti-racist challenges for Saskatchewan. Canadian Journal of Political Science, 39(3), 507-527.

Gur, 0. (2010). Persons with mental illness in the criminal justice system: Police interventions to prevent violence and criminalization. Journal of Police Crisis Negotiations, 10, 220-240.

lacobucci, F. (2014). Police Encounters with people in crisis. Toronto Police.

Kelly, B. (2005). Structural violence and schizophrenia. Social Science and Medicine, 61(3), 721-730.

Lamanna, D., Shapiro, G., Kirst, M., Matheson, F., Nakhost, A., \& Stergipoulos, V. (2018). Co-responding police-mental health programmes: Service user experiences and outcomes in a large urban centre. International Journal of Mental Health Nursing, 27, 891-900.

Lamb, H. R., Weinberger, L. E., \& DeCuir, W. J. (2002). The police and mental health. Psychiatric Services, 53(10), 1266-1271.

Liegghio, M. (2017). Our biggest hurdle yet: Caregivers' encounters with structural stigma in child and youth mental health. Families in Society, 98(4), 300-309.

Liegghio, M., \& Jaswal, P. (2015). Police encounters in child and youth mental health: Could stigma-informed crisis intervention training (CIT) for parents help? Special Issue on Mental Health: Journal of Social Work Practice: Psychotherapeutic Approaches in Health, Welfare and the Community, 29(3), 301-319.

Liegghio, M., Truong, A., Canas, H., \& Al-Bader, H. (2020). "I don't want people to think I'm a criminal": Calling for more compassionate policing in child and youth mental health. Journal of Community Safety and Wellbeing, 5(3), 120-126
Liegghio, M., Van Katwyk, T., Freeman, B., Caragata, L., Sdao-Jarvie, K., Brown, K., \& Sandha, A. (2017). Police involvement among a community population of children and youth accessing mental health services. Social Work in Mental Health, 15(1), 14-27.

Livingston, J., Desmarais, S., Verdun-Jones, S., Parent, R., Michalak, E., \& Brink, J. (2014). Perceptions and experiences of people with mental illness regarding their interactions with police. International Journal of Law and Psychiatry, 37(4), 334-340.

Lord, V., \& Bierregaard, B. (2014). Helping persons with mental illness: Partnerships between police and mobile crisis units. Victims and Offenders, 9, 455-474.

Miller, C., \& Vittrup, B. (2020). The indirect effects of police racial bias on African American families. Journal of Family Issues, 41(10), 1699-1722.

Morabito, M., Kerr, A., Watson, A., Draine, J., Ottati, V., \& Angell, B. (2012). Crisis intervention teams and people with mental illness: Exploring the factors that influence the use of force. Crime \& Delinquency, 58(1), 57-77.

Moskos, M., Olson, L., Halbern, S., \& Gray, D. (2007, April). Utah youth suicide study: Barriers to mental health treatment for adolescents. Suicide and Life-Threatening Behavior, 37(2), 179-186.

Odgers, C., Burnette, M., Chauhan, P., Moretti, M., \& Reppucci, D. (2005). Misdiagnosing the problem: Mental health profiles of incarcerated juveniles. The Canadian Child and Adolescent Psychiatry Review, 14(1), 26-29.

Peterson-Badali, M., McCormick, S., Vitopoulos, N., Davis, K., Haqanee, Z., \& Skilling, T. A. (2015). Mental health in the context of Canada's youth justice system. Canadian Criminal Law Review, 19(1), 5-20.

Robst, J., Armstrong, M., Dollard, N., \& Rohrer, L. (2013). Arrests among youth after out-of-home mental health treatment: Comparisons across community and residential treatment settings. Criminal Behaviour and Mental Health, 23, 162-176.

Sestoft, D., Rasmussen, M., Vitus, K., \& Kongsrund, L. (2014). The police, social services and psychiatry cooperation in Denmark - A new model of working practice between governmental sectors. A description of the concept, process, practice and experience. International Journal of Law and Psychiatry, 37, 370-375.

Sloly, P. (25 January, 2021). Report to Ottawa Police Services Board: Consultation approach for mental health response strategy. Ottawa, ON: Ottawa Police Services. https://www.ottawapolice.ca/en/ news-and-community/Reports-and-Publications.aspx

Vander Koep, A., Evens, C., \& Taub, J. (1997). Risk of juvenile justice system referral among children in a public mental health system. Journal of Behavioral Health Sciences and Research, 24(4), 428-442.

Watson, A., Angell, B., Morabito, M., \& Robinson, N. (2008). Defying negative expectations: Dimensions of fair and respectful treatment by police officers as perceived by people with mental illness. Administration and Policy in Mental Health and Mental Health Services Research, 35(6), 449-457

Weiss, R. (1994). Learning from strangers: The art and method of qualitative interview studies. The Free Press.

Wolff, N. (2005). Community reintegration of prisoners with mental illness: A social investment perspective. International Journal of Law and Psychiatry, 28(1), 43-58.

Yang, S. M., Gill, C., Kanewske, L. C., \& Thompson P. S. (2018). Exploring police response to mental health calls in a nonurban area: A case study of Roanoke County, Virginia. Victims and Offenders, 13(18), 1132-1152. 